\title{
PPAR $\gamma$ potentiates anticancer effects of gemcitabine on human pancreatic cancer cells
}

\author{
HIRONORI KOGA ${ }^{1,2}$, KARUPPAIYAH SELVENDIRAN ${ }^{1}$, RAMADOSS SIVAKUMAR ${ }^{1}$, \\ TAKAFUMI YOSHIDA ${ }^{1,2}$, TAKUJI TORIMURA ${ }^{1,2}$, TAKATO UENO ${ }^{1}$ and MICHIO SATA ${ }^{1,2}$ \\ ${ }^{1}$ Research Center for Innovative Cancer Therapy, and Center of the 21 st Century Center of \\ Excellence Program for Medical Science, Kurume University; ${ }^{2}$ Division of Gastroenterology, \\ Department of Medicine, Kurume University School of Medicine, Kurume, Japan
}

Received August 5, 2011; Accepted September 26, 2011

DOI: 10.3892/ijo.2011.1237

\begin{abstract}
In order to improve the prognosis of patients with unresectable pancreatic cancer, there is an urgent need for enhancement of the anticancer effect of gemcitabine $(\mathrm{Gem})$, a first-line drug for the disease. Here, we demonstrated that ligands for peroxisome proliferator-activated receptor $\gamma$ $(\operatorname{PPAR} \gamma)$ such as pioglitazone (Pio) and rosiglitazone potentiated the cytotoxic action of Gem on human pancreatic cancer cells in a dosage-dependent manner. Notably, the synergistic effect was PPAR $\gamma$-dependent, since the effect was augmented by PPAR $\gamma$ overexpression and was attenuated by both a PPAR $\gamma$ inhibitor (GW9662) and PPAR $\gamma$-specific siRNA. To further increase the collaborative effect, the histone deacetylase (HDAC) inhibitor valproic acid (VPA), a known potentiator for PPAR $\gamma$ function, was added to the combinatorial treatment, robustly inducing apoptosis mediated by highly expressed death receptors, including Fas/CD95 and DR5. In xenograft tumor experiments in nude mice, Gem plus Pio significantly suppressed tumor growth as compared with the control treatment, while Gem-only treatment did not. Triple treatment with Gem, Pio, and VPA failed to demonstrate a significant antitumor effect when compared with Gem plus Pio in the current setting. Considered together, Gem plus PPAR $\gamma$ ligands, including Pio, may have therapeutic advantage in the treatment of advanced pancreatic cancer. Since Pio is widely used in the treatment of diabetes mellitus, it may become a feasible partner of Gem-based chemotherapy, fine-tuning the strength of the therapy in a dosage-dependent fashion.
\end{abstract}

Correspondence to: Dr Hironori Koga, Division of Gastroenterology, Department of Medicine, Kurume University School of Medicine, 67 Asahi-machi, Kurume 830-0011, Japan

E-mail: hirokoga@med.kurume-u.ac.jp

Key words: chemotherapy, peroxisome proliferator-activated receptor, thiazolidinedione, synergy, HDAC inhibitor, siRNA, death receptor, caspase, xenograft

\section{Introduction}

Gemcitabine (Gem) has been a first-line chemotherapeutic drug for unresectable pancreatic cancer for more than a decade $(1,2)$. Although many chemotherapeutic attempts combining Gem with other cytotoxic or biological agents have been tested, no obvious clinical benefit has been achieved to date $(2,3)$. In the post-Gem-only era for the treatment of advanced pancreatic cancer, there is an urgent need to explore not only novel and powerful chemotherapeutic agents, but also combinatorial drugs with Gem that are significantly effective.

Peroxisome proliferator-activated receptor $\gamma$ (PPAR $\gamma$ ) is a nuclear hormone receptor whose synthetic ligands, thiazolidinediones (TZDs), exhibit antiproliferative and/or apoptosis-inducing effects on several malignant cell types (4-7), although the main therapeutic target of the ligands is non-insulin-dependent diabetes mellitus (NIDDM). PPAR $\gamma$ is expressed in human pancreatic cancer cells (8), and receptor-directed treatment of cancer cells with TZDs, including pioglitazone and rosiglitazone, has been demonstrated to be valid through inducement of differentiation, cell cycle arrest, and apoptosis (4-6). Among the unique pharmacological effects of TZDs, an anti-inflammatory effect via inhibition of nuclear factor- $\kappa \mathrm{B}(\mathrm{NF}-\kappa \mathrm{B})$ activity has become the focus in the control of inflammatory diseases (9). However, the TZD effect on NF- $\kappa B$ has not attracted much attention in cancer therapy. Recently, it was suggested that an NF- $\mathrm{KB}$ suppressor could act as a chemosensitizer when used in combination with other conventional anticancer drugs, augmenting apoptosis of cancer cells through suppression of survival signals in the cells (10). Based on this rationale, we speculate that TZDs (PPAR $\gamma$ ligands) harboring dual properties as anticancer drugs and chemosensitizers could be chemotherapeutic partners of Gem in the treatment of advanced pancreatic cancer. Here, we report a synergistic apoptosis-inducing effect of Gem and TZDs on human pancreatic cancer cells in a PPAR $\gamma$-dependent manner both in vitro and in vivo. Furthermore, since it is known that PPAR $\gamma$ action is enhanced by histone deacetylase (HDAC) inhibitors $(11,12)$, we attempted to determine whether any additive cytotoxic effects could be obtained from triple treatment with Gem, TZDs, and the HDAC inhibitor valproic acid (VPA), which is an orally prescribed anti-convulsant drug. 


\section{Materials and methods}

Cell lines and cultures. Human pancreatic cancer cell lines BxPC-3,PANC-1, and MIAPaCa-2 were obtained from American Type Culture Collection (Manassas, VA). The cells were grown in Dulbecco's modified Eagle's medium (Sigma-Aldrich Japan, Tokyo, Japan) supplemented with $10 \%$ heat-inactivated $\left(56^{\circ} \mathrm{C}\right.$, $30 \mathrm{~min}$ ) fetal bovine serum (BioWest, Nuaill, France), $100 \mathrm{U} / \mathrm{ml}$ penicillin, and $100 \mu \mathrm{g} / \mathrm{ml}$ streptomycin (Invitrogen, Carlsbad, $\mathrm{CA}$ ) in a humidified atmosphere of $5 \% \mathrm{CO}_{2}$ at $37^{\circ} \mathrm{C}$.

Chemicals. Pioglitazone (Pio) was obtained from Takeda Pharmaceutical Co. Ltd. (Osaka, Japan). Rosiglitazone (Rosi) and gemcitabine hydrochloride (Gem) were obtained from BioVision Research Products (Mountain View, CA) and Eli Lilly Japan K.K. (Kobe, Japan), respectively. GW9662, a PPAR $\gamma$ antagonist; clofibrate, a PPAR $\alpha$ agonist; trichostatin A (TSA), a histone deacetylase (HDAC) inhibitor; and dimethyl sulfoxide (DMSO) were obtained from Sigma-Aldrich Japan. VPA, an HDAC1 inhibitor, was obtained from Wako Pure Chemical Industries, Ltd. (Osaka, Japan).

Enzyme-linked immunosorbent assay (ELISA) for NF- $\mathrm{B} B$. Nuclear extracts from cells were obtained using NE-PER ${ }^{\circledR}$ Nuclear and Cytoplasmic Extraction Reagents (Thermo Scientific, Rockford, IL). A TransAM ${ }^{\mathrm{TM}}$ NF-kB p65 kit (Active Motif, Carlsbad, CA) was utilized to evaluate transcriptional activity of NF- $\kappa \mathrm{B}$ semi-quantitatively according to the manufacturer's protocol. The developed color in the incubated samples was measured with an ARVO $^{\mathrm{TM}}$ MX (PerkinElmer Japan Co., Ltd., Tokyo, Japan).

Western blot analysis. Western blot analyses using $35 \mu \mathrm{g}$ of protein from each sample were performed as previously described (13). The primary antibodies used were for poly(ADP) ribose polymerase (PARP), Akt, Ser473-phosphorylated (p-) Akt, death receptor (DR) 5, tumor necrosis factor receptor (TNFR) 1, TNFR2, cleaved caspase-3, caspase-7, and caspase-8 (Cell Signaling Technology, Beverly, MA), PPAR $\alpha$, PPAR $\gamma$, actin (Santa Cruz Biotechnology, Santa Cruz, CA), Fas/CD95 clone DX2 (BD Biosciences, Franklin Lakes, NJ), and Fas/ CD95 clone CH-11 (MBL, Nagoya, Japan). Cells were lysed in lysis buffer [50 mmol/1 Tris- $\mathrm{HCl}(\mathrm{pH} 8.0), 150 \mathrm{mmol} / \mathrm{l} \mathrm{NaCl}$, $0.5 \%$ Nonidet P-40, $1 \mathrm{mmol} / \mathrm{l}$ EDTA (pH 8.0), 1 mmol/1 EGTA ( $\mathrm{pH}$ 8.0), $0.1 \mathrm{mmol} / 1$ sodium fluoride $(\mathrm{NaF}), 0.1 \mathrm{mmol} / 1$ sodium orthovanadate $\left(\mathrm{Na}_{3} \mathrm{VO}_{4}\right), 1 \mathrm{mmol} / 1$ dithiothreitol, $2 \mathrm{~g} / \mathrm{ml}$ aprotinin, and $2 \mathrm{~g} / \mathrm{ml}$ leupeptin]. Cell lysates were centrifuged, and the supernatants were separated. The protein concentration was measured using a Bio-Rad protein assay kit (Bio-Rad, Hercules, CA). After being boiled for $5 \mathrm{~min}$ in 2-mercaptoethanol, samples containing cell lysate protein were separated on $8 \%, 10 \%$, or $15 \%$ SDS-polyacrylamide gels and then transferred onto equilibrated polyvinylidene difluoride membranes (Bio-Rad). After skimmed milk blocking, the membranes were incubated with the primary antibodies described above. The bound antibodies were detected with horseradish peroxidase-labeled sheep anti-mouse IgG or horseradish peroxidase-labeled donkey antirabbit IgG (Amersham Pharmacia Biotech, Buckinghamshire, UK) using an enhanced chemiluminescence detection system (ECL Advance kit, Amersham). A positive signal from the target proteins was visualized using a LAS-1000plus image analyzer (Fujifilm, Tokyo, Japan), and the signal intensity was determined semi-quantitatively using an Image Gauge version 3.45 (Fujifilm).

PPAR $\gamma$ overexpression and gene silencing. A plasmid carrying full-length PPAR $\gamma_{2}$ cDNA (FLAG-tagged) was a kind gift from Professor Shigeaki Kato (Tokyo University, Japan) (14). For PPAR $\gamma$ overexpression experiments or PPAR $\gamma$ knocking-down experiments, BxPC-3 cells were grown to $60 \%-70 \%$ confluence in 60-mm dishes. The PPAR $\gamma_{2}$ cDNA plasmid was transfected using Lipofectamine (Invitrogen). The empty vector-transfected cells were used as the controls. In the PPAR $\gamma$ knocking-down experiments, cells were transfected with either $100 \mathrm{nM}$ PPAR $\gamma$ SMARTpool siRNA or control (non-targeting; NT) siRNA (Dharmacon, Lafayette, CO) for $24 \mathrm{~h}$ using Oligofectamine (Invitrogen) according to the manufacturer's instruction. Cells were collected $48 \mathrm{~h}$ after transfection and total cell lysates were used in the Western blot analysis described above. This experiment was performed in triplicate using independent sets of treated samples.

Inhibition of xenografted tumor growth in nude mice by Gem, Pio and VPA. Cultured BxPC- 3 cells $\left(10^{7}\right.$ per mouse) were subcutaneously (s.c.) injected into the back of 5-week-old male $\mathrm{BALB} / \mathrm{c}$ athymic nude mice (Clea Japan, Osaka, Japan). At 5 to 7 days later, when the largest diameter of the tumors measured $\sim 5-7 \mathrm{~mm}$, the mice were divided into 5 groups ( $\mathrm{n}=10$ each) in a manner that would equalize the mean tumor diameter between the groups. Mice receiving Gem only were administered $20 \mathrm{mg} /$ $\mathrm{kg}$ of Gem in $50 \mu \mathrm{l}$ of saline intraperitoneally (i.p.) twice a week. Pio $(25 \mathrm{mg} / \mathrm{kg}$ in $50 \mu \mathrm{l}$ of DMSO) and VPA (50 mg/kg in $50 \mu \mathrm{l}$ of saline) were also administered i.p., respectively. The control group received corresponding media. Xenografted tumor size was measured weekly in 2 orthogonal directions using calipers, and the tumor volume $\left(\mathrm{mm}^{3}\right)$ was estimated using the equation length $\mathrm{x}$ (width) $)^{2} \times 0.5$. The mice were sacrificed at 5 weeks after administration of the agents. All animal experiments were conducted in accordance with the NIH Guidelines for the Care and Use of Laboratory Animals and were approved by the University of Kurume Institutional Animal Care and Use Committee.

Statistical analysis. Statistical significance was assessed using the Mann-Whitney U test. $\mathrm{P}<0.05$ was considered statistically significant.

\section{Results}

Inhibition of NF- $\kappa B$ by PPAR ligands. BxPC-3 cells were treated with $1 \mu \mathrm{M} \mathrm{Gem}$ for $0,0.5,1$ and $2 \mathrm{~h}$, and then the prepared nuclear extracts were immediately subjected to NF- $\mathrm{kB}$ ELISA. Significantly higher activity was observed at 0.5 and $1 \mathrm{~h}(\mathrm{P}<0.01)$ than that observed prior to treatment, and the elevation returned to baseline at $2 \mathrm{~h}$ (Fig. 1A). At $30 \mathrm{~min}$, pioglitazone $(10 \mu \mathrm{M})$ significantly attenuated the Gem-induced activation of NF- $\mathrm{KB}$ (Fig. 1B).

Enhancement of Gem-induced apoptosis by PPAR $\gamma$ ligands. Incubation with Gem at a final concentration of $1 \mu \mathrm{M}$ for $24 \mathrm{~h}$ induced apoptosis in BxPC-3 cells, displayed by increased 
A

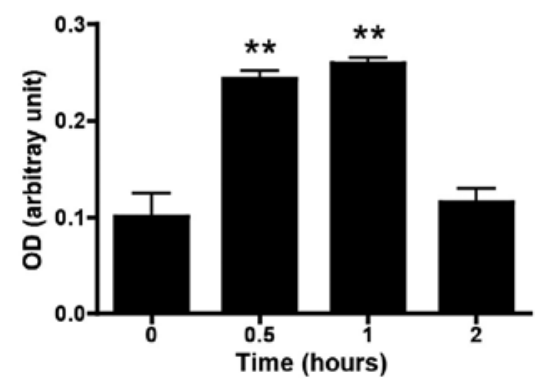

B

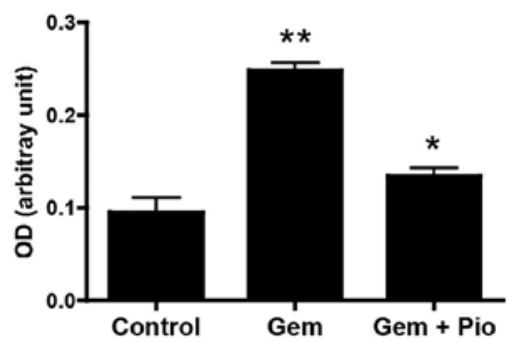

Figure 1. (A) Nuclear extracts from BxPC-3 cells treated with $1 \mu \mathrm{M}$ gemcitabine (Gem) for the indicated time were prepared, and the NF- $\mathrm{kB}$ transcriptional activity in the extracts was analyzed semi-quantitatively by ELISA. ${ }^{* *} \mathrm{P}<0.01$. (B) Under the same culture condition at 30 min, pioglitazone (Pio) (10 $\left.\mu \mathrm{M}\right)$ significantly attenuated Gem-induced activation of NF-kB. Control, vehicle-treated cells. "P<0.05. Error bars in (A) and (B) indicate mean (SD) obtained from 3 independent experiments carried out in duplicate.

A

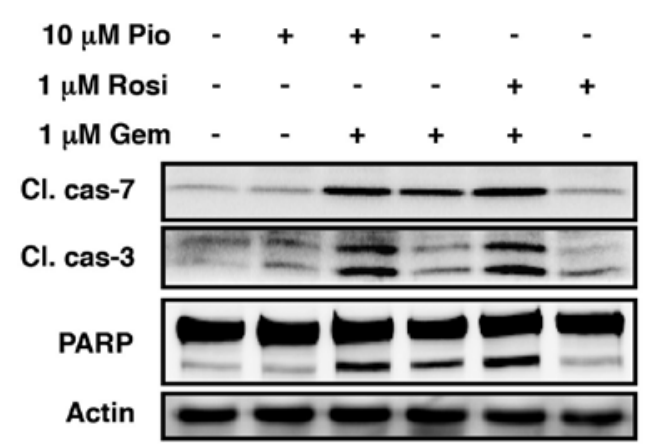

B

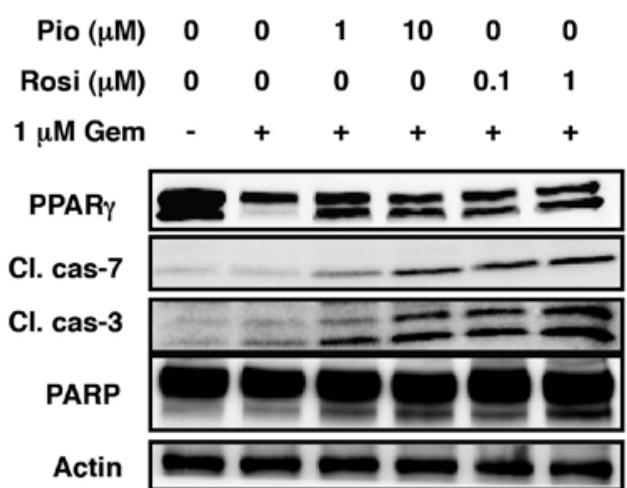

C
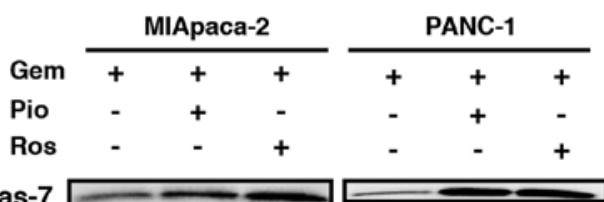

Cl. cas-7
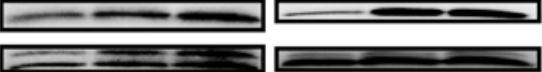

Cl. cas-3

PARP

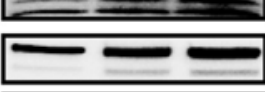

Actin

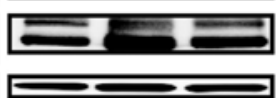

Figure 2. (A) BxPC-3 cells were treated with Gem, Pio, rosiglitazone (Rosi), or combinations of Gem plus Pio or Gem plus Rosi for 24 h, and their total cell lysates were subjected to Western blot analysis to assess cell apoptosis. Cl. cas, cleaved caspase; PARP, poly(ADP)ribose polymerase. (B) Addition of Pio and Rosi to Gem, respectively, enhanced apoptosis in a dosage-dependent manner. (C) The apoptosis-promoting effect of Pio (10 $\mu \mathrm{M})$ and Rosi (1 $\mu \mathrm{M})$ is also observed in MIAPaCa-2 and PANC-1 cells, demonstrating cleavage in the caspases and PARP.

expression levels of cleaved PARP and cleaved caspase-7, an executer caspase. Under this condition, we first screened for possible enhancement of apoptosis in the cells exposed to Gem with or without PPAR $\gamma$ ligands. The PPAR $\gamma$ ligands Pio and Rosi clearly increased the expression levels of cleaved caspase-7, cleaved caspase-3, and cleaved PARP at $24 \mathrm{~h}$ after treatment. No clear apoptosis from single treatment with each PPAR $\gamma$ ligand was detected in this study (Fig. 2A). Next, we assessed dosage-dependent enhancement of Gem-induced apoptosis by the 2 PPAR $\gamma$ ligands. Both Pio and Rosi promoted Gem-induced apoptosis, resulting in a clear increase in the expression levels of cleaved caspase- 3 and cleaved PARP (Fig. 2B). Endogenous expression of both PPAR $\gamma_{1}$ and PPAR $\gamma_{2}$ was detected in the untreated condition; however, the expression level of PPAR $\gamma_{1}$ (Fig. 2B; bottom band) was strikingly decreased in treatment with Gem alone. This decrease was cancelled out by the addition of Pio and Rosi, respectively (Fig. 2B). Similar enhancement of apoptosis was also observed in MIAPaCa- 2 and PANC- 1 cells, where cleavage in the caspases and PARP were demonstrated (Fig. 2C).

PPAR $\gamma$-dependent enhancement of apoptosis. To clarify whether there was definite enhancement by Pio and Rosi of Gem-induced apoptosis through PPAR $\gamma$, we investigated the effects of PPAR $\gamma$ overexpression, inhibition of PPAR $\gamma$ function, and specific down-regulation of PPAR $\gamma$ expression on enhanced 
A

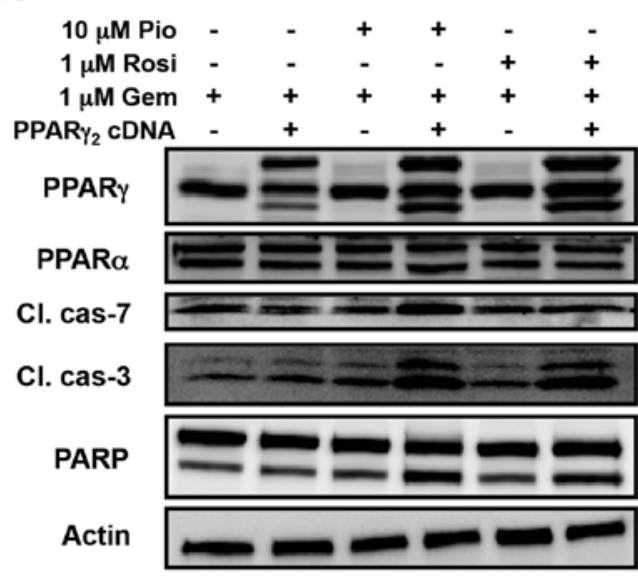

B

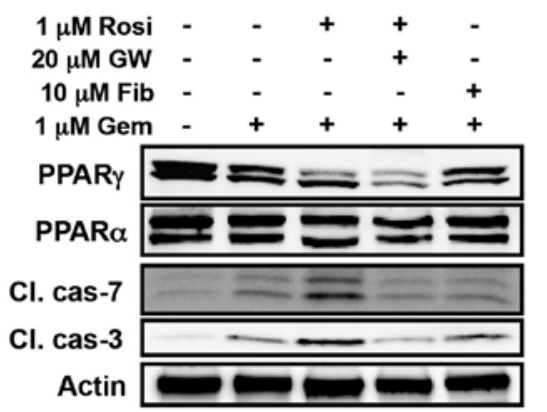

C

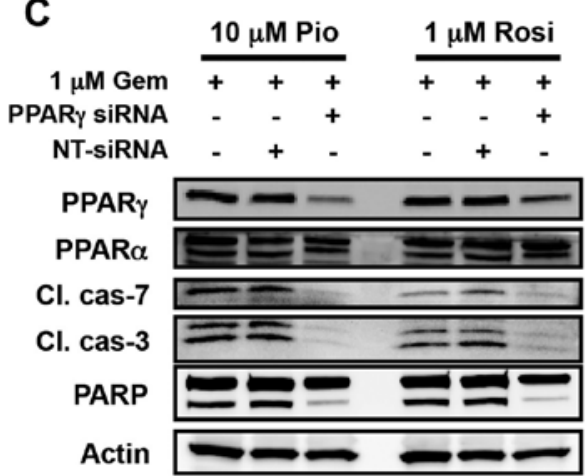

Figure 3. (A) Both empty vector-transfected cells and PPAR $\gamma$-overexpressing cells were treated with Gem alone or Gem plus Pio/Rosi for $24 \mathrm{~h}$, and their total cell lysates were collected to assess apoptosis by Western blot analysis. Bands for PPAR $\gamma$, including one that was myc-tagged (top), indicate efficient transfection of the gene into the cells. Expression level of PPAR $\alpha$ was unaltered by the treatments. Note robust signal for cleaved caspase-3 (Cl. cas-3) in the PPAR $\gamma$-overexpressing cells treated with Gem plus Pio/Rosi. Cl. cas-7, cleaved caspase-7. (B) Cells were treated with the indicated agents and concentrations for $24 \mathrm{~h}$, and whole cell lysates were examined by Western blotting. The PPAR $\gamma$ antagonist GW9662 (GW) $(20 \mu \mathrm{M})$ downregulates endogenous expression levels of PPAR $\gamma$ and cancels out PPAR $\gamma$ ligand (Rosi)-dependent enhancement of apoptosis in an obvious manner. Clofibrate (Fib), a PPAR $\alpha$ agonist, does not modulate the cytotoxic effect of Gem in the cells. (C) NT-siRNA, non-targeting small interfering RNA. Note striking decrease in the expression levels of Cl. cas-3, Cl. cas-7, and cleaved PARP (lower bands) in the cells co-incubated with Gem and Pio or Rosi, respectively.

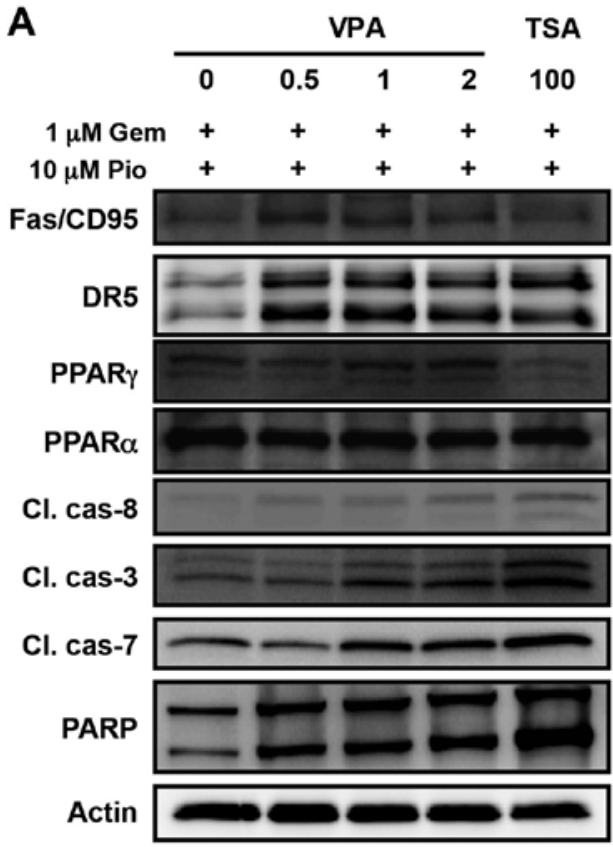

B
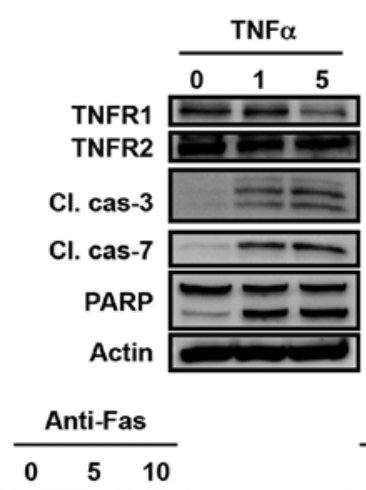

Fas/CD95

Cl. cas-3

Cl. cas-7

PARP

Actin

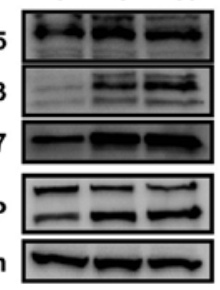

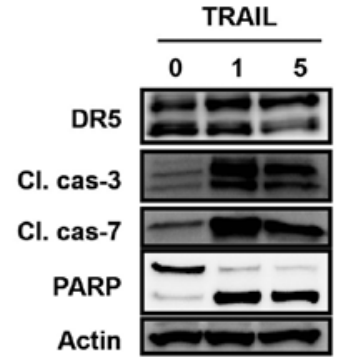

Figure 4. (A) BxPC-3 cells were simultaneously treated with Gem, Pio, and valproic acid (VPA) (mg/ml) for $24 \mathrm{~h}$, and protein expressions of the indicated molecules were examined by Western blotting. DR5, death receptor 5. The HDAC inhibitor trichostatin (TSA) (ng/ml) was used as a positive control for HDAC inhibitormediated enhancement of apoptosis induced by Gem plus Pio. (B) Cells were pretreated with $1 \mu \mathrm{M} \mathrm{Gem}, 10 \mu \mathrm{M}$ Pio, and $0.5 \mathrm{mg} / \mathrm{ml} \mathrm{VPA}$ for $12 \mathrm{~h}$, and were subsequently co-incubated with the death receptor ligands TNF $(1 \mathrm{ng} / \mathrm{ml})$, anti-Fas/CD95 antibody $(5 \mathrm{ng} / \mathrm{ml})$ (clone CH-11), and TRAIL (1 ng/ml), respectively. Caspases- 3 and -7 are clearly activated in the cells exposed to the ligands. 
apoptosis by Pio and Rosi (Fig. 3). PPAR $\gamma$ overexpression by transfection with PPAR $\gamma_{2}$ cDNA demonstrated 3 distinct bands in the Western blot analysis for PPAR $\gamma$, indicated by the expression of myc-tagged PPAR $\gamma_{2}$ (top), endogenous PPAR $\gamma_{2}$ (middle), and endogenous PPAR $\gamma_{1}$ (bottom) (Fig. 3A). The BxPC-3 cells were exposed to Gem alone $(1 \mu \mathrm{M})$ or Gem plus PPAR $\gamma$ ligand with or without PPAR $\gamma$ overexpression. After $24 \mathrm{~h}$ treatment, a striking amount of apoptosis was observed in the PPAR $\gamma$-overexpressing cells treated with Gem plus PPAR $\gamma$ ligand, accompanied by a clear increase in the expression levels of cleaved caspase-3 and cleaved PARP (Fig. 3A). The expression level of PPAR $\alpha$ in the cells was unaltered by any of the treatments in this study. Next, we examined the functional involvement of PPAR $\gamma$ in the augmentation of Gem-induced apoptosis using the PPAR $\gamma$ antagonist GW9662 (Fig. 3B). Simultaneous treatment with GW9662 $(20 \mu \mathrm{M})$ cancelled out augmentation of apoptosis by Gem plus Rosi, which was clearly demonstrated by decreased expression levels of cleaved caspase-7 and cleaved caspase-3. The PPAR $\alpha$ agonist clofibrate did not exert any synergistic effects on Gem in inducing apoptosis in these cells (Fig. 3B). The siRNA treatment to knock down PPAR $\gamma$ expression specifically suppressed expression levels of PPAR $\gamma$ by less than $25 \%$ of that in cells treated with the NT siRNA or the vehicle. In concert with the forced decrease of PPAR $\gamma_{2}$ expression levels by the specific siRNA treatment, a striking decrease in the expression levels of cleaved caspase-3, cleaved caspase-7, and cleaved PARP was observed in the cells co-incubated with Gem and the PPAR $\gamma$ ligands, leading to clear attenuation in apoptosis (Fig. 3C).

Additive effects of HDAC inhibitors on the combination of Gem and PPAR $\gamma$ ligands. Because HDAC inhibitors are known to enhance PPAR $\gamma$ activity, we conducted triple treatment with Gem, Pio, and VPA. In combination treatment with $1 \mu \mathrm{M}$ Gem plus $10 \mu \mathrm{M}$ Pio, VPA of up to a final concentration of $2 \mathrm{mg} / \mathrm{ml}$ was added to the BxPC-3 cell culture medium. Enhanced apoptosis was observed in these cells in a VPA dosage-dependent manner in comparison with that of the Gem plus Pio combination (Fig. 4A). Apoptosis reached near-maximum levels at $1 \mathrm{mg} / \mathrm{ml}$ VPA. From mechanistic points of view, we investigated the protein expression levels of death receptors, including Fas/ CD95 and DR5, and found that their expression levels were increased by the addition of VPA (Fig. 4A). TSA $(100 \mathrm{ng} / \mathrm{ml})$ displayed a similar protein expression profile to the apoptosisrelated molecules used in this study (Fig. 4A). To validate the functional involvement of death receptors such as TNFR1, Fas/ CD95, and DR5 in apoptosis, the cells treated with $1 \mu \mathrm{M}$ Gem plus $10 \mu \mathrm{M}$ Pio plus $0.5 \mathrm{mg} / \mathrm{ml}$ VPA were incubated with the death receptor ligands TNF $\alpha$, anti-Fas/CD95 antibody (CH-11), and TRAIL, respectively (Fig. 4B). The 3 ligands effectively induced apoptosis in the pancreatic cancer cells at $1 \mathrm{ng} / \mathrm{ml} \mathrm{TNF} \alpha$, $5 \mathrm{ng} / \mathrm{ml}$ anti-Fas/CD95 antibody, and $1 \mathrm{ng} / \mathrm{ml}$ TRAIL, respectively, clearly indicating that the VPA-induced death receptors were functional (Fig. 4B).

Inhibition of xenografted tumor growth by Gem-based combination treatments. The anti-cancer potential of Gem-based combination treatments in vivo was investigated in a xenograft model in nude mice. Although treatment with Gem alone did not result in any statistically significant decrease in tumor

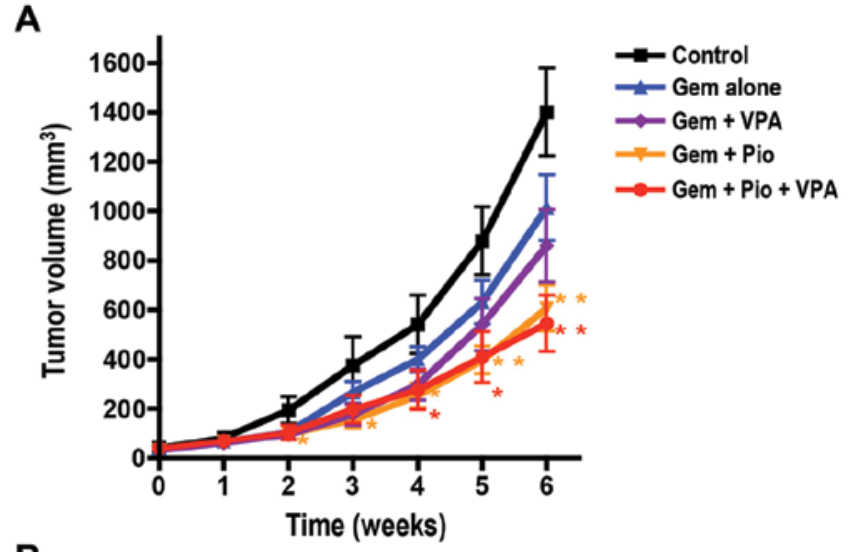

B

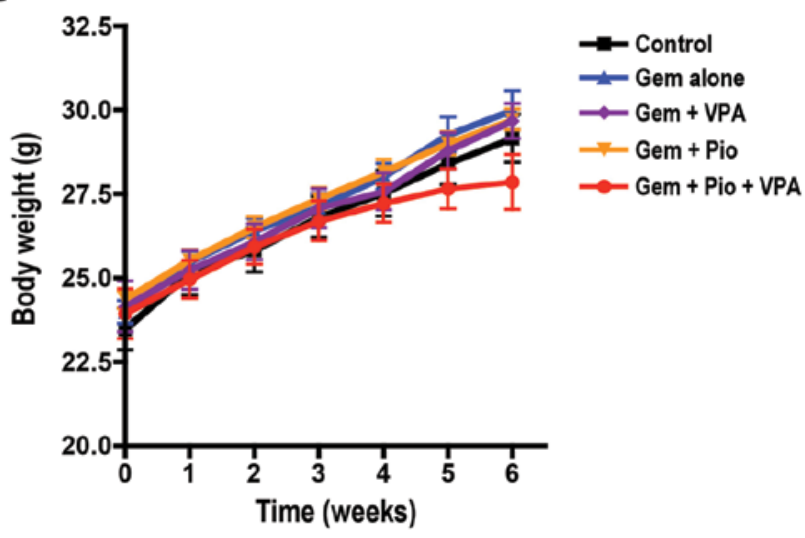

Figure 5. (A) Growth curves of BxPC-3 cell-derived xenograft tumors in nude mice. Error bars indicate mean (SD). ${ }^{*} \mathrm{P}<0.05$ and ${ }^{* *} \mathrm{P}<0.01$ versus control. (B) Mean (SD) body weight of each treated mice group. Details of treatments are described in Materials and methods.

volume during the experimental period in this study, the Gem plus Pio treatment began to decrease tumor volume significantly 2 weeks after treatments were initiated, compared with that of the control treatment (Fig. 5A). A significant decrease in tumor volume was also observed after 3 weeks of the triple treatment comprising Gem, Pio, and VPA (Fig. 5A). When comparing the tumor volume in combination treatments with that of Gem-only treatment, the combination of Gem plus VPA and the triple treatment of Gem, Pio and VPA caused statistically significant decrease $(\mathrm{P}<0.05)$ at 5 and 6 weeks and at 6 weeks of treatment, respectively. The tumor volume in the Gem plus VPA treatment group was not significantly decreased in comparison with that of the control group or the Gem-alone group at any time points. The body weight of the mice was measured weekly to monitor tolerance to the treatments (Fig. 5B). There was no significant difference between all treatment groups; however, the triple treatment group recorded lower body weight with a $\mathrm{P}=0.065$ compared with that of the Gem-alone group at both 5 and 6 weeks of treatment (Fig. 5B).

\section{Discussion}

In the present study, we have initially demonstrated the following: i) PPAR $\gamma$ stimulation by TZDs enhanced Gem-induced apoptosis in human pancreatic cancer cells. ii) Treatment with Gem 
plus Pio significantly inhibited xenografted tumor growth without severe body weight loss in nude mice in comparison to treatments with PBS (control) and with Gem alone. iii) The HDAC inhibitor further potentiated the cytotoxic effect of the Gem plus Pio combination by upregulating the expression of death receptors such as TNFR1, Fas/CD95, and DR5 in vitro.

Responsible genes and their products have been explored with cDNA microarray analysis and proteomics to overcome Gem resistance in pancreatic cancer cells (15). However, the molecules identified so far by these analyses may need more time prior to their clinical application. Currently, many researchers approve of the strategy of combining Gem with other anticancer agents, including S-1 (16), although the prognostic outcome of the tested combinations has not always been significantly improved (17). One of the main reasons for the limited progress in the layered use of multiple anticancer drugs is myelosuppression that is more severe than that appearing in Gem-only treatment (18). To minimize such severe toxicities and to maximize the beneficial effects, molecular targeted drugs, including erlotinib (19), have been included in recent clinical trials (20). Although molecular targeted drugs displayed promising potential in the pre-clinical phases, improvement in overall survival in phase III trials remained marginal $(21,22)$.

Under these circumstances, the potential of NF- $\mathrm{kB}$ inhibition as another rationale for chemosensitization was evaluated in the present study (10,23-25). Indeed, Pio and Rosi, which possess $\mathrm{NF}-\kappa \mathrm{B}$-inactivating properties, augmented chemosensitivity to Gem in pancreatic cancer cells. More importantly, the enhanced chemosensitivity was initially found to be PPAR $\gamma$-dependent, implying that the combinatorial cytotoxic effect could be managed by adjusting the dosage of PPAR $\gamma$ ligands administered without a great need to alter the optimal Gem dosage. Furthermore, since the PPAR $\gamma$ ligands (TZDs) chosen for this study are widely used to treat NIDDM, a major complication of pancreatic cancer (26), the combined use of TZDs with Gem would be another feasible option for treatment of the disease in a clinical setting.

Although inactivation of NF- $\mathrm{\kappa B}$ is generally believed to potentiate chemosensitivity in various types of cancer cells (10), due attention should be paid to unwanted failure of chemosensitization despite NF-kB suppression (27). Since TZDs are not professional inhibitors of NF- $\mathrm{KB}$, the possibility of failure would be anticipated and thus should be avoided, especially when the combination treatment of Gem plus TZDs is brought into clinical use. Therefore, to ensure and potentiate the anticancer effect of the combination, we conducted stimulation with PPAR $\gamma$, thereby increasing the PPAR $\gamma$-dependent cytotoxic activity of Gem. For this purpose, an HDAC inhibitor was chosen as a partner for the combination, since the inhibitor is known to fine-tune PPAR $\gamma$ function through modulation of direct interaction between PPAR $\gamma$ and HDACs (11). As expected, the HDAC inhibitor VPA clearly augmented the apoptosis-inducing effect of the Gem plus TZD combination, at the very least, by upregulating death receptors in vitro. This encouraging finding prompted us to perform xenograft experiments with the Gem, Pio, and VPA triple treatment. However, there was no significant decrease in xenografted tumor volume in the triple-treatment nude mice compared to those treated with Gem plus Pio, which was probably due to malnutrition in the mice.
Although the 3-drug animal experiment in this study did not always support bedside application of the triple treatment, it clearly depicted the advantageous effect of Gem plus Pio combination therapy, providing insights into a novel strategy to potentiate the effect of Gem on advanced pancreatic cancer. In addition, from an economic point of view, it suggests that TZD-based potentiation of Gem will be more affordable than other methods of adding multiple anti-cancer drugs to Gem. These points are being assessed in the phase II clinical trial currently conducted at our hospital.

\section{Acknowledgements}

We would like to thank Masako Hayakawa for technical assistance. This study was supported by grants from the following: a project for establishing new high-technology research centers and the 21st Century COE Program for Medical Science (the Japan Ministry of Education, Culture, Sports, Science, and Technology), the Kobayashi Institute for Innovative Cancer Chemotherapy, and the Pancreas Research Foundation of Japan.

\section{References}

1. Burris HA III, Moore MJ, Andersen J, et al: Improvements in survival and clinical benefit with gemcitabine as first-line therapy for patients with advanced pancreas cancer: a randomized trial. J Clin Oncol 15: 2403-2413, 1997.

2. Hidalgo M: Pancreatic cancer. N Engl J Med 362: 1605-1617, 2010.

3. Wang Z, Li Y, Ahmad A, Banerjee S, Azmi AS, Kong D and Sarkar FH: Pancreatic cancer: understanding and overcoming chemoresistance. Nat Rev Gastroenterol Hepatol 8: 27-33, 2011.

4. Sarraf P, Mueller E, Jones D, et al: Differentiation and reversal of malignant changes in colon cancer through PPAR $\gamma$. Nat Med 4: 1046-1052, 1998.

5. Motomura W, Okumura T, Takahashi N, Obara T and Kohgo Y: Activation of peroxisome proliferator-activated receptor $\gamma$ by troglitazone inhibits cell growth through the increase of $\mathrm{p} 27^{\mathrm{KiPl}}$ in human pancreatic carcinoma cells. Cancer Res 60: 5558-5564, 2000.

6. Eibl G, Wente MN, Reber HA and Hines OJ: Peroxisome proliferator-activated receptor $\gamma$ induces pancreatic cancer cell apoptosis. Biochem Biophys Res Commun 287: 522-529, 2001.

7. Koga H, Sakisaka S, Harada M, et al: Involvement of $\mathrm{p} 21^{\mathrm{WAF} 1 / \mathrm{Cip1}}$, $\mathrm{p} 27^{\mathrm{Kip} 1}$, and $\mathrm{p} 18^{\mathrm{INK} 4 \mathrm{c}}$ in troglitazone-induced cell-cycle arrest in human hepatoma cell lines. Hepatology 33: 1087-1097, 2001.

8. Kristiansen G, Jacob J, Buckendahl AC, et al: Peroxisome proliferator-activated receptor $\gamma$ is highly expressed in pancreatic cancer and is associated with shorter overall survival times. Clin Cancer Res 12: 6444-6451, 2006.

9. Su CG, Wen X, Bailey ST, et al: A novel therapy for colitis utilizing PPAR- $\gamma$ ligands to inhibit the epithelial inflammatory response. J Clin Invest 104: 383-389, 1999.

10. Nakanishi $C$ and Toi M: Nuclear factor- $\kappa B$ inhibitors as sensitizers to anticancer drugs. Nat Rev Cancer 5: 297-309, 2005.

11. Fajas L, Egler V, Reiter R, et al: The retinoblastoma-histone deacetylase 3 complex inhibits PPAR $\gamma$ and adipocyte differentiation. Dev Cell 3: 903-910, 2002.

12. Annicotte JS, Iankova I, Miard S, et al: Peroxisome proliferatoractivated receptor $\gamma$ regulates E-cadherin expression and inhibits growth and invasion of prostate cancer. Mol Cell Biol 26: 7561-7574, 2006.

13. Koga H, Harada M, Ohtsubo M, et al: Troglitazone induces $\mathrm{p} 27^{\mathrm{Kipl}}$ _ associated cell-cycle arrest through down-regulating Skp2 in human hepatoma cells. Hepatology 37: 1086-1096, 2003.

14. Kodera Y, Takeyama K, Murayama A, Suzawa M, Masuhiro Y and Kato S: Ligand type-specific interactions of peroxisome proliferator-activated receptor $\gamma$ with transcriptional coactivators. J Biol Chem 275: 33201-33204, 2000.

15. Kuramitsu Y, Taba K, Ryozawa S, et al: Identification of up- and down-regulated proteins in gemcitabine-resistant pancreatic cancer cells using two-dimensional gel electrophoresis and mass spectrometry. Anticancer Res 30: 3367-3372, 2010. 
16. Ioka T, Ikeda M, Ohkawa S, et al: GEST study group. Randomized phase III study of gemcitabine plus S-1 (GS) versus S-1 versus gemcitabine (GEM) in unresectable advanced pancreatic cancer (PC) in Japan and Taiwan: GEST study. J Clin Oncol 29: (suppl) abstr 4007, 2011.

17. Long J, Zhang Y, Yu X, et al: Overcoming drug resistance in pancreatic cancer. Expert Opin Ther Targets 15: 817-828, 2011

18. Conroy T, Desseigne F, Ychou M, et al: Groupe Tumeurs Digestives of Unicancer; PRODIGE Intergroup. FOLFIRINOX versus gemcitabine for metastatic pancreatic cancer. N Engl J Med 364: 1817-1825, 2011.

19. Moore MJ, Goldstein D, Hamm J, et al: National Cancer Institute of Canada Clinical Trials Group. Erlotinib plus gemcitabine compared with gemcitabine alone in patients with advanced pancreatic cancer: a phase III trial of the National Cancer Institute of Canada Clinical Trials Group. J Clin Oncol 25: 1960-1966, 2007.

20. Wong HH and Lemoine NR: Pancreatic cancer: molecular pathogenesis and new therapeutic targets. Nat Rev Gastroenterol Hepatol 6: 412-422, 2009.

21. Philip PA, Benedetti J, Corless CL, et al: Phase III study comparing gemcitabine plus cetuximab versus gemcitabine in patients with advanced pancreatic adenocarcinoma: Southwest Oncology Group-directed intergroup trial S0205. J Clin Oncol 28: 3605-3610, 2010.
22. Saif MW: Does erlotinib restore chemosensitivity to chemotherapy in pancreatic cancer? A case series. Anticancer Res 31: 1039-1042, 2011.

23. Kallifatidis G, Rausch V, Baumann B, et al: Sulforaphane targets pancreatic tumour-initiating cells by NF- $\kappa \mathrm{B}$-induced antiapoptotic signalling. Gut 58: 949-963, 2009.

24. Banerjee S, Kong D, Azmi AS, et al: Restoring sensitivity to oxaliplatin by a novel approach in gemcitabine-resistant pancreatic cancer cells in vitro and in vivo. Int J Cancer 128: 1240-1250, 2011.

25. Pan X, Arumugam T, Yamamoto T, et al: Nuclear factor- $\kappa \mathrm{B}$ p65/ relA silencing induces apoptosis and increases gemcitabine effectiveness in a subset of pancreatic cancer cells. Clin Cancer Res 14: 8143-8151, 2008.

26. Bao B, Wang Z, Li Y, et al: Complexities of obesity and diabetes mellitus with the development and progression of pancreatic cancer. Biochim Biophys Acta 1815: 135-146, 2011.

27. Mamaghani S, Patel S and Hedley DW: Glycogen synthase kinase-3 inhibition disrupts nuclear factor- $\kappa B$ activity in pancreatic cancer, but fails to sensitize to gemcitabine chemotherapy. BMC Cancer 9: 132, 2009. 